\title{
Individual and school environment factors associated with overweight in adolescents of the municipality of Rio de Janeiro, Brazil
}

\author{
Letícia de Oliveira Cardoso 1,*, Inês Rugani Ribeiro de Castro ${ }^{2,3}$, \\ Fabio da Silva Gomes ${ }^{4}$ and luri da Costa Leite ${ }^{1}$ \\ 'Escola Nacional de Saúde Pública, Fundação Oswaldo Cruz/Ministério da Saúde, Rua Leopoldo Bulhões \\ 1480, Manguinhos, Rio de Janeiro, CEP 21041 -210, RJ, Brazil: ${ }^{2}$ Instituto de Nutrição, Universidade do Estado \\ do Rio de Janeiro, Rio de Janeiro, RJ, Brazil: ${ }^{3}$ Instituto de Nutrição Annes Dias, Secretaria Municipal de Saúde \\ do Rio de Janeiro, Rio de Janeiro, RJ, Brazil: ${ }^{4}$ Área de Alimentação, Nutrição e Câncer, Coordenação de \\ Prevenção e Vigilância, Coordenação Geral de Ações Estratégicas, Instituto Nacional de Câncer/Ministério da \\ Saúde, Rio de Janeiro, RJ, Brazil
}

Submitted 9 February 2010: Accepted 7 October 2010: First published online 28 January 2011

\begin{abstract}
Objective: To identify the association of individual and school environment factors with overweight among adolescents.

Design: Cross-sectional study. Sociodemographic and behavioural information was collected using an anonymous self-administered questionnaire. Indicators on human and physical resources of the schools were based on information collected in interviews with school principals. Overweight was defined based on the BMI Z-score for age and sex recommended by WHO. Logistic regression models were used for statistical analysis.

Setting: Rio de Janeiro, Brazil.

Subjects: By means of a two-stage (classrooms and students) probabilistic sampling, subjects comprised 1632 students enrolled in the last year of primary education of the municipal public school network, stratified by city region.

Results: The mean prevalence of overweight at schools was $17 \cdot 2 \%$, ranging from $0 \%$ to $50 \%$. Adolescents more likely to be overweight were those who attended schools without knives and forks or ceramic/glass plates for students in the school refectory (prevalence odds ratio $(\mathrm{POR})=1.40 ; P=0.04$ ), those whose head of household had completed between 8 and 10 years of schooling $(\mathrm{POR}=1 \cdot 46$; $P=0 \cdot 03$ ), those who did not live with both parents ( $\mathrm{POR}=1 \cdot 24 ; P=0 \cdot 06)$ and those who had not practised physical activity outside school on at least $1 \mathrm{~d}$ in the $7 \mathrm{~d}$ before the study (POR $=1 \cdot 56 ; P=0 \cdot 04$ ).

Conclusions: Sociodemographic and behavioural variables of adolescents and school characteristics were associated with overweight, confirming individual and context effects on this health disorder. Studies such as the present one, identifying variables in context, may support actions to prevent overweight among adolescents.
\end{abstract}

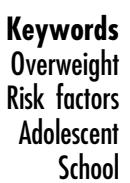

The concern of health professionals and authorities with the development and consequences of overweight on population health in several parts of the world is unquestionable. The WHO states that obesity is currently one of the most relevant and also one of the most neglected public health problems ${ }^{(1)}$.

Although some studies have revealed a plateau and even a drop in the prevalence of overweight among children and adolescents in some countries of Europe in recent years ${ }^{(2-4)}$, in general terms the estimates of past decades are alarming. In the USA, the number of overweight children and adolescents has doubled and tripled, respectively, since 1980 . Overweight is not restricted to developed countries; its increase has been even faster in developing countries ${ }^{(5)}$. Overweight (including obesity) in Brazilian adolescents has speeded up. Between 1974 and 2003 , the prevalence grew from $3 \cdot 2$ to $12 \cdot 6 \%{ }^{(6)}$.

Several authors agree that the change observed in the prevalence of overweight in increasingly younger individuals is due mainly to factors related to individual and family behaviours and the characteristics of the environment in which children and youth live. Literature reviews (that have analysed information of developing and developed countries) have highlighted that the total 
amount of energy from the diet, the frequency of consumption of soft drinks, the absence of breast-feeding in the beginning of life, the frequency and intensity of exercising, the time spent in sedentary activities (mainly the amount of time watching television), having one or both parents obese and the socio-economic level of parents, among other factors, are associated with overweight in childhood or adolescence ${ }^{(7-9)}$. Specifically in developing countries, some factors have stood out in the literature: the fast growth and weight gain in early childhood ${ }^{(10,11)}$ and aspects related to diet, such as the number of meals and the unsatisfactory standard of having meals ${ }^{(12,13)}$. Studies on the influence of the environment on the occurrence of obesity are relatively recent. For about a decade, Swinburn et $a l^{(14)}$ have been drawing attention to the relevance of different contexts on the determination of obesity and to the need to take into account these contexts in interventions aimed at the prevention and control of obesity. Therefore, also recent are the epidemiological investigations assessing the effect of variables related to the home, neighbourhood and school environment on overweight during childhood and adolescence. Characteristics of schools have been less studied. Lee $e t a l^{(15)}$ have observed that schools with a higher percentage of students receiving low-price meals have a higher proportion of obese students even after adjusting for median income of the school neighbourhood. The studies mentioned were performed in high-income countries. No studies that investigated the effect of the environment (neighbourhood and/or school) on the occurrence of overweight during adolescence and the association between this outcome and environment variables adjusted by individual factors have been identified in low- and middle-income countries to date.

Identifying school characteristics that may explain variations in the individual level of overweight represents an important tool in building and/or redirecting evidencebased interventions. Our assumption is that some characteristics of the school scenario may explain the variability in the prevalence of overweight in adolescents. Therefore, the objective of the present study was to identify the association between individual and school environment factors and overweight in adolescents enrolled in public schools of the city of Rio de Janeiro, the second largest Brazilian metropolis.

\section{Methods}

\section{Data source}

Data examined in the present paper were extracted from the second survey (held between September and November 2007) that comprises the surveillance system on health risks of adolescents implemented in the city of Rio de Janeiro. Details on the concept and implementation of the system have been described elsewhere ${ }^{(16)}$. A complex survey sample was designed to produce representative estimates of the population of students enrolled in the last year of primary education in municipal public schools of Rio de Janeiro. The school network had 1082 schools and 743416 students in 2007, distributed in ten regions of the city. Schools were divided into ten strata according to the region of the city, and there were two sampling units (i.e. classrooms and students). Within each natural stratum (city regions), classrooms were selected using the probability proportional to size sampling procedure, in which the size was defined as the number of students in the classroom. In the next stage, eligible students were selected by means of a simple random sample, with a preset size of ten students per class. The estimate of the sample size totalled 1700 students, distributed in 170 classes and 136 schools, aimed at a lower sampling error, due to the resources available for the study. The students selected who accepted to take part in the study, presented a consent form signed by one of their parents/guardians, were present on the day of data collection at school, answered the questionnaire and participated in the anthropometric assessment were included in the survey. From the 1700 eligible students, fifty-two students were lost due to absence on the day scheduled for the study and the lack of an informed consent form signed by a parent; of the remaining 1648, sixteen were lost due to lack of information on sex or age. The resulting effective sample size was thus 1632. The study was approved by the Committee of Ethics in Research with Humans of the Rio de Janeiro Municipal Health Department.

The questionnaire for students was based on tools already used in surveillance systems on risk factors of youth in other countries ${ }^{(17,18)}$ and tested with students in the last two years of primary education of a public school of the municipality. The tool was built to be self-administered and anonymous, gathering information on: sociodemographic characteristics; food consumption and behaviours; physical activity; sedentary leisure habits; consumption of cigarettes, alcohol and other drugs; sexual health; safety; oral health; body image; and relationships with family, friends and school. During the questionnaire test-retest assessment, estimates of $\kappa, \kappa$ adjusted for prevalence (when prevalence was higher than $80 \%$ and lower than $20 \%$ ) and quadratic weighted $\kappa$ (for ordinal variables) were observed to vary between 0.34 (habit of eating while watching television or studying) and 0.99 (sex and age). Most questions (60\%) had $\kappa$ values above $0 \cdot 61$, a substantial level according to Landis and $\mathrm{Koch}^{(19)}$. Information on the level of schooling of the head of household was provided by guardians in a form attached to the consent form.

Weight and height were measured by trained researchers and standardized techniques ${ }^{(20,21)}$. In order to obtain weight, a portable solar scale (Tanita ${ }^{\circledR} \mathrm{BF} / \mathrm{BC}-$ HS301: Tokyo, Japan) with maximum capacity of $150 \mathrm{~kg}$ and accuracy of $0 \cdot 2 \mathrm{~kg}$ was used. A portable stadiometer (AlturExata ${ }^{\circledR}$; Belo Horizonte, Brazil), with the main scale in centimetres and having $0 \cdot 1 \mathrm{~cm}$ accuracy, was used to 
measure height. Measurements obtained were examined with regard to heterogeneity of terminal digits, and retraining and standardization were performed to minimize the occurrence of measurement errors. Measured height and weight were used to calculate adolescents' BMI (weight in kilograms divided by the square of height in metres) in order to define their nutritional status.

Information on schools was obtained by means of an interview with the school principal and by direct observation made by researchers on the day scheduled for data collection. Information was collected on: the availability of human and physical resources; the performance of educational and health promotion activities at the school; resources related to the National School Food Program (NSFP); and the sale and advertisement of food at school.

\section{Variables and indicators}

\section{Outcome}

BMI for age and sex was used to diagnose the nutritional status of adolescents, adopting WHO cut-offs ${ }^{(22)}$ which define the presence of overweight as BMI $Z$-score $\geq 1$.

\section{Independent individual and school variables}

The following individual variables were considered in the present study: age (in complete years); skin colour; sex; total number of appliances in the household (0 to 9) and presence of a maid more than $5 \mathrm{~d}$ /week; living with mother and father; years of schooling of the head of household $(0-7$; $8-10$; $\geq 11$ ); frequency of food consumption (raw salad, cooked vegetables, fresh fruit, milk, fried snacks, sweet cookies, soft drinks) in the past $7 \mathrm{~d}$ (0 to $7 \mathrm{~d})$; usual number of meals/d (0 to 6); habit of having breakfast; weekly frequency of the presence of one of the parents/guardians during meals ( 0 to 6 times/week; every day); habit of eating or snacking while watching television or studying; use of medication or induction of vomiting to lose weight in the past $30 \mathrm{~d}$; time (minutes accumulated) practising physical activity inside and outside school, with and without the guidance of a teacher, and travel on foot or by bicycle to school in the past $7 \mathrm{~d}$; practising physical activity outside school on at least $1 \mathrm{~d}$ in the past $7 \mathrm{~d}$; number of hours watching television daily; using the computer for $\geq 6 \mathrm{~h} / \mathrm{d}$; trying cigarettes and alcoholic beverages; and smoking among parents or guardians (none of the parents/guardians; one of the parents/guardians; both parents/guardians).

Variables analysed related to the school environment were: availability of human and physical resources (ratio between number of students enrolled and active teachers; percentage of physical education teachers over total active teachers; ratio between number of students enrolled and active physical education teachers; presence of a refectory, covered sports court and computer labs with Internet access; ratio of working drinking water fountains over existing drinking water fountains; ratio between number of students enrolled and working drinking water fountains); performance of educational activities (presence of educational, sports and health projects at school; partnerships with other public and private institutions); resources related to NSFP (availability of knives and forks or ceramic/glass plates in the school refectory); sale and advertisement of food at school (presence and what kind of food and beverage); population density in the school neighbourhood (number of inhabitants/ha); and presence of vendors around the school (sidewalks surrounding the school).

\section{Statistical analysis}

\section{Treatment of missing data}

Of the 1648 students studied, approximately 3\% ( $n$ 54) did not have information on weight and height. The main reasons for the lack of this information were refusal to participate in measuring and very extreme values registered. The imputation process for these variables was performed by modelling the present data as predictors for missing data and extreme values, and adding residuals of the adjusted model ${ }^{(23)}$. Adolescents who did not have information on sex and/or age ( $n$ 16) were discarded, given these variables were used as ancillary to imputation.

The variable schooling of the head of household had a very high percentage of losses due to incomplete questionnaires (30.3\%) and non-response (8.6\%). Given losses were not randomly distributed. These missing data were imputed using the classification tree procedure, a multivariate non-parametric classification technique that enables one to identify which values would be imputed in the variable considered ${ }^{(24)}$.

Of the 136 schools studied, three principals were not present at the time of collecting data and were not able to answer the questionnaire. Therefore, information was collected on 133 schools.

\section{Data analysis}

The database was built with double entry, using the Entry module of the EpiData program (EpiData Association, Odense, Denmark) ${ }^{(25)}$.

In order to identify variables associated with overweight, two modelling procedures were used. Initially we used a multilevel logistic regression with two levels, schools and students ${ }^{(26,27)}$, to assess how much the variability of overweight occurrence could be explained by the school level. However, in the null model the variance of the random effect of the school was observed not to be different from zero, indicating that no percentage of the variability of overweight occurrence in this population could be attributed to the school. Then, a one-level logistic regression model was used. The analysis was done in two stages. In the first, univariate logistic regression models were used and all variables statistically significant at the level of $25 \%$ were initially selected for the multiple model. For numeric variables, adjustments in the presence of quadratic terms were also carried out. The variables selected were divided into groups (school variables; sociodemographic variables of adolescents and family; family behaviours; adolescent 
Table 1 Characteristics of schools and their locations, Rio de Janeiro Public Municipal School Network, 2007

\begin{tabular}{|c|c|c|c|c|}
\hline \multirow[b]{2}{*}{ Variable/indicator } & \multicolumn{3}{|c|}{ Summary measurements } & \multirow[b]{2}{*}{$\%$ of missing data } \\
\hline & Min-max & Mean & SD & \\
\hline No. of students enrolled & $252-1870$ & $955 \cdot 8$ & $320 \cdot 7$ & - \\
\hline No. of active teachers & $11-102$ & $43 \cdot 4$ & $15 \cdot 8$ & 0.8 \\
\hline No. of active physical education teachers & $1-13$ & $4 \cdot 8$ & $1 \cdot 7$ & - \\
\hline Ratio of no. of students to no. of active teachers & $10 \cdot 5-66 \cdot 7$ & $23 \cdot 1$ & $7 \cdot 71$ & $0 \cdot 8$ \\
\hline Ratio of no. of students to no. of physical education teachers & $77 \cdot 3-670 \cdot 0$ & $249 \cdot 8$ & $83 \cdot 0$ & - \\
\hline Percentage of physical education teachers at school & $3 \cdot 45-23 \cdot 3$ & $9 \cdot 8$ & $3 \cdot 1$ & $0 \cdot 8$ \\
\hline Ratio of no. of students to no. of working water fountains & $63-1721$ & $328 \cdot 3$ & $280 \cdot 1$ & 0.8 \\
\hline Percentage of working water fountains at school & $33 \cdot 3-100 \cdot 0$ & $91 \cdot 5$ & $17 \cdot 5$ & $0 \cdot 8$ \\
\hline No. of students/class & $25 \cdot 8-47 \cdot 2$ & $35 \cdot 3$ & $4 \cdot 6$ & - \\
\hline \multirow[t]{2}{*}{ Population density of school neighbourhood (inhabitants/ha) } & $2 \cdot 00-359 \cdot 00$ & $98 \cdot 6$ & $6 \cdot 2$ & - \\
\hline & $n$ & \multicolumn{2}{|c|}{$\%$} & \\
\hline \multicolumn{5}{|c|}{ Presence of physical resources } \\
\hline \multicolumn{5}{|c|}{ Covered sports court, auditorium and computer lab with Internet access } \\
\hline Yes & 34 & \multirow{2}{*}{\multicolumn{2}{|c|}{$\begin{array}{l}25 \cdot 6 \\
74 \cdot 4\end{array}$}} & - \\
\hline No & 99 & & & \\
\hline \multicolumn{5}{|c|}{ Presence of knives and forks and glass/ceramic plates at school refectory } \\
\hline Some of them & 103 & & $0 \cdot 8$ \\
\hline None of them & 29 & \multicolumn{2}{|c|}{$22 \cdot 0$} & \\
\hline \multicolumn{5}{|l|}{ Educational activities and partnerships } \\
\hline \multicolumn{5}{|l|}{ Outside-class activities for students and community } \\
\hline Yes & 77 & \multirow{2}{*}{\multicolumn{2}{|c|}{$\begin{array}{l}59 \cdot 7 \\
40 \cdot 3\end{array}$}} & - \\
\hline No & 56 & & & \\
\hline \multicolumn{5}{|c|}{ Participation in Municipal Health Department health promotion programme } \\
\hline Yes & 25 & \multirow{2}{*}{\multicolumn{2}{|c|}{$\begin{array}{l}18 \cdot 8 \\
81 \cdot 2\end{array}$}} & - \\
\hline No & 108 & & & \\
\hline \multicolumn{5}{|l|}{ Partnership with other public institutions and private institutions } \\
\hline Yes & 58 & \multicolumn{2}{|c|}{$\begin{array}{l}43.6 \\
56.4\end{array}$} & - \\
\hline No & 42 & & & \\
\hline \multicolumn{5}{|l|}{ Partnership with municipal sports project } \\
\hline Yes & 22 & \multirow{2}{*}{\multicolumn{2}{|c|}{$\begin{array}{l}16 \cdot 7 \\
83 \cdot 3\end{array}$}} & $0 \cdot 8$ \\
\hline No & 110 & & & \\
\hline \multicolumn{5}{|l|}{ Any kind of food selling inside school } \\
\hline Yes & 2 & \multirow{2}{*}{\multicolumn{2}{|c|}{$\begin{array}{r}1.5 \\
98.5\end{array}$}} & - \\
\hline No & 131 & & & \\
\hline \multicolumn{5}{|l|}{ Any kind of food and beverage selling around school } \\
\hline Yes & 76 & \multirow{2}{*}{\multicolumn{2}{|c|}{$\begin{array}{l}58 \cdot 9 \\
41 \cdot 1\end{array}$}} & 3.0 \\
\hline No & 53 & & & \\
\hline
\end{tabular}

behaviours), then multiple models were generated for each block separately, and statistically significant variables at the level of $5 \%$ were identified. After this stage a new multiple model was generated with the introduction of variables in the order of the blocks presented here, and the final model again comprised the variables significant at the level of $5 \%$ after adjustment by the variables of the previous block. Sex and age of the adolescents were kept regardless of the $P$ value associated with the estimate of the prevalence odds ratio (POR) of these variables. Variables with a borderline $P$ value $(0.05$ and 0.06$)$ were kept in the final model. The SPSS statistical software package version 17 (SPSS Inc., Chicago, IL, USA) was used.

\section{Results}

The number of adolescents evaluated ranged between three and thirty in the schools studied (mean $13 \cdot 78$, SD $5 \cdot 32$ ). The mean age of the students was $15 \cdot 07$ (SD 0.04) years. Most of the students included were girls $(55 \cdot 1 \%)$, rated themselves as brown or mulato $(45.0 \%)$ and lived with both parents $(52 \cdot 9 \%)$. On average, the families of adolescents had $7 \cdot 13$ (SD 0.04) appliances, most frequently a stove, refrigerator and television, and a bathroom inside the house (minimum of $99.5 \%)$, and less frequently they owned a car $(35.2 \%)$ or a motorcycle $(8 \cdot 8 \%)$. Less than $5 \%$ of adolescents lived in homes that had a maid on $5 \mathrm{~d} /$ week or more. As for education, most of the heads of household had completed 7 years of schooling $(45.5 \%)$. The proportion of overweight ranged between 0 and $50 \%$ in schools, with an overall proportion of $17 \cdot 2$ (sD $10 \cdot 4) \%$. We observed that the mean proportion of overweight among schools in the first quartile of this variable was about four times lower than for the schools in the last quartile $(7 \cdot 2 \%$ and $30 \cdot 4 \%$, respectively).

Schools presented a wide variation in availability of human and physical resources (Table 1). The minority of schools had a covered sports court, auditorium and computer lab with Internet connection (25\%), areas and equipment that help in the development of sports 
Table 2 Individual factors associated with overweight among adolescents enrolled in public schools of the municipality of Rio de Janeiro, 2007: univariate analyses

\begin{tabular}{|c|c|c|c|}
\hline Variable/indicator & Non-adjusted POR & $95 \% \mathrm{Cl}$ & $P$ value* \\
\hline \multicolumn{4}{|l|}{ Sociodemographic } \\
\hline \multicolumn{4}{|l|}{ Sex } \\
\hline Female & 1.00 & & \\
\hline Male & 0.85 & $0 \cdot 65,1 \cdot 12$ & 0.22 \\
\hline Age (years) $\dagger$ & $11 \cdot 13$ & $0.73,16 \cdot 9$ & 0.08 \\
\hline \multicolumn{4}{|c|}{ Years of study completed by head of household } \\
\hline $0-7$ & $1 \cdot 00$ & & \\
\hline $8-10$ & $1 \cdot 47$ & $0.90,1.89$ & $0 \cdot 15$ \\
\hline$\geq 11$ & $1 \cdot 31$ & $1 \cdot 06,2 \cdot 03$ & 0.02 \\
\hline \multicolumn{4}{|c|}{ Presence of father and mother at home } \\
\hline Yes & $1 \cdot 00$ & & \\
\hline No & $1 \cdot 26$ & $0.97,1.63$ & 0.09 \\
\hline \multicolumn{4}{|c|}{ Behavioural } \\
\hline \multicolumn{4}{|c|}{ Consumption of selected foods in past $7 \mathrm{~d}$} \\
\hline Raw saladt & $0 \cdot 82$ & $0.68,0.99$ & 0.04 \\
\hline Fried snacks & 1.06 & $0.99,1 \cdot 13$ & 0.08 \\
\hline Sweet cookies & 1.05 & $1 \cdot 00,1 \cdot 11$ & 0.05 \\
\hline \multicolumn{4}{|c|}{$\begin{array}{l}\text { Presence of at least one of the parents or other person responsible } \\
\text { for the student in at least one meal }\end{array}$} \\
\hline 0-6 times/week & $1 \cdot 19$ & $0.92,1.54$ & $0 \cdot 19$ \\
\hline Every day & 1.00 & & \\
\hline \multicolumn{4}{|c|}{ Eating or snacking while watching television or studying } \\
\hline Yes & $1 \cdot 62$ & $1 \cdot 03,2 \cdot 56$ & 0.04 \\
\hline No & $1 \cdot 00$ & & \\
\hline \multicolumn{4}{|c|}{ Using the computer for $\geq 6 \mathrm{~h} / \mathrm{d}$} \\
\hline Yes & $1 \cdot 36$ & $0.97,1.92$ & 0.07 \\
\hline No & $1 \cdot 00$ & & \\
\hline \multicolumn{4}{|c|}{ Practising physical activity outside school on at least $1 \mathrm{~d}$ in past $7 \mathrm{~d}$} \\
\hline Yes & 1.00 & & \\
\hline No & $1 \cdot 57$ & $1 \cdot 09,2 \cdot 25$ & 0.02 \\
\hline
\end{tabular}

and educational activities. Only two schools sold food inside their facilities. Of the schools evaluated, a small percentage participated in health programmes and sports projects (18.8\% and $16 \cdot 7 \%$, respectively).

Individual variables associated with overweight at a $25 \%$ significance level are shown in Table 2. The age of adolescents had a quadratic relationship with overweight, as did the intake of raw salad in the $7 \mathrm{~d}$ before the study. Among behaviours included, the ones that presented the strongest associations were: the habit of eating or snacking while watching television or studying; and not practising physical activity outside school on at least $1 \mathrm{~d}$ in the previous $7 \mathrm{~d}$. Schooling of the head of household presented an inverted U-shaped relationship with overweight: the chance of prevalence of overweight was higher among adolescents whose head of household had intermediate education (8-10 complete years of schooling) compared with adolescents whose head of household had less or more schooling. Other sociodemographic characteristics like skin colour, total number of appliances in the household and presence of a maid for $5 \mathrm{~d}$ /week or more did not present an association with overweight; nor did some behaviours related to diet, time dedicated to physical activity practice or habit of watching television. Behaviours like trying cigarettes or alcoholic beverages and using medication or induction of vomiting to lose weight did not present statistically significant associations either.

Still in the univariate analyses, adolescents who attended schools with a covered sports court, auditorium and computer lab with Internet connection, that provided knives and forks or ceramic/glass plates in the school refectory, that were engaged in partnerships with municipal sport projects and that were located in areas with a smaller population density were less likely to be overweight (Table 3).

In the multiple analyses, the unavailability of knives and forks or ceramic/glass plates for students in the school refectory was the only characteristic of the school that remained in the final model, increasing the adolescent's chance of being overweight by $40 \%$. As for individual factors, schooling of the head of household had the same association pattern identified in the univariate analysis and remained in the final model. Not living with both parents and not practising physical activity outside school on at least $1 \mathrm{~d}$ of the past $7 \mathrm{~d}$ were directly associated with the occurrence of overweight (Fig. 1).

\section{Discussion}

The multilevel analysis did not identify a context effect (school) on study outcomes. Our original hypothesis, that 
Table 3 School characteristics associated with overweight among adolescents enrolled at public schools of the municipality of Rio de Janeiro, 2007: univariate analyses

\begin{tabular}{|c|c|c|c|}
\hline Variable/indicator & Non-adjusted POR & $95 \% \mathrm{Cl}$ & $P$ value* \\
\hline \multicolumn{4}{|c|}{$\begin{array}{l}\text { Physical resources } \\
\text { Existence of covered sports court, auditorium and computer lab linked to the Internet }\end{array}$} \\
\hline $\begin{array}{l}\text { Yes } \\
\text { No }\end{array}$ & $\begin{array}{l}1 \cdot 00 \\
1 \cdot 20\end{array}$ & $0 \cdot 88,1 \cdot 64$ & $0 \cdot 25$ \\
\hline \multicolumn{4}{|c|}{$\begin{array}{l}\text { Resources related to school meals programme } \\
\text { Availability of knives and forks and ceramic/glass plates at school refectory }\end{array}$} \\
\hline $\begin{array}{l}\text { None of them } \\
\text { Some of them }\end{array}$ & $\begin{array}{l}1 \cdot 00 \\
0 \cdot 76\end{array}$ & $0.57,1.03$ & 0.08 \\
\hline \multicolumn{4}{|l|}{$\begin{array}{l}\text { Educational activities and partnerships } \\
\text { Partnership with municipal sports project }\end{array}$} \\
\hline $\begin{array}{l}\text { Yes } \\
\text { No }\end{array}$ & $\begin{array}{l}1 \cdot 00 \\
1 \cdot 29\end{array}$ & $0 \cdot 88,1 \cdot 88$ & $0 \cdot 20$ \\
\hline $\begin{array}{l}\text { Characteristics of school location } \\
\text { Population density of school neighbourhood (inhabitants/ha) }\end{array}$ & $1 \cdot 01$ & $0.99,1.03$ & $0 \cdot 21$ \\
\hline
\end{tabular}

POR, prevalence odds ratio.

${ }^{*} P$ value of Wald statistics.

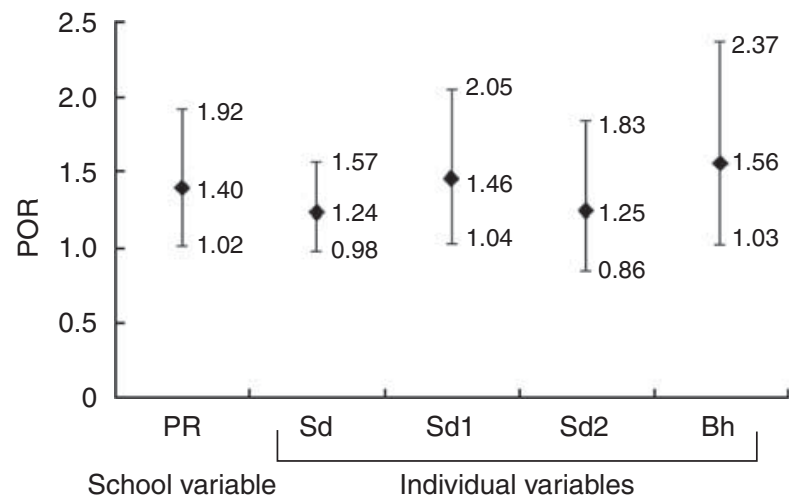

Fig. 1 Characteristics of the school and individual associated with overweight among adolescents enrolled in public schools of the municipality of Rio de Janeiro, 2007. Prevalence odds ratio (POR), with 95\% confidence interval represented by vertical bars, adjusted according to blocks of variables: PR (physical resources), knives and forks or glass/ceramic plates not available at school refectory; Sd (sociodemographic), not having both parents living in the same household as the adolescent; Sd1 (sociodemographic 1), head of household had 8-10 years of schooling; Sd2 (sociodemographic 2), head of household had $\geq 11$ years of schooling; Bh (behavioral), not exercising outside school on at least $1 \mathrm{~d}$ in the past $7 d$

the school environment could explain the variation in the overweight proportion, was not confirmed in this population. This can be explained because of the sample design, which was not representative at the level of schools, and because a concentration of overweight frequency was not observed in any group of schools. Among the results of the few studies that tested this hypothesis, a small proportion of BMI variation (3-5\%) was found to be related to school $^{(28,29)}$. Other studies have also suggested that the school environment may influence behaviours associated with health, such as the different patterns in the consumption of alcohol, tobacco and physical activity practised by adolescents ${ }^{(30-33)}$.

The only school characteristic that presented a statistically significant association with the presence of overweight among adolescents was the availability of ceramic/glass plates and/or knives and forks in the school refectory. The public schools of the municipality of Rio de Janeiro are assisted by the NSFP, which is supported by municipal and federal governments and complies with national guidelines ${ }^{(34)}$. The city's departments of health and education have developed some actions to improve this programme ${ }^{(35)}$. One of these actions was the incentive to change plastic plates for glass/ceramic plates and spoons for knives and forks, especially to encourage adolescents to have the balanced meals offered by school and avoid eating snacks with high energy and low nutrient density. This and other actions have been implemented heterogeneously among schools. Unfortunately, it was not possible to identify how this variable contributed to the reduction of the chance of prevalence of overweight among adolescents. We may assume that this is a marker variable to identify the schools that adhered more easily to NSFP's improvement recommendations or that were more concerned with the development of health promotion and healthy diet actions, which would promote healthier behaviours among adolescents, and could partly explain the results of the present study.

Indicators used in the present study as markers of socio-economic level (total number of appliances in the household and presence of a maid working regularly in the household) were observed not to be associated with overweight. However, the years of schooling of the head of the family were associated with overweight. Recent papers reveal that the association between socioeconomic markers and overweight has changed its dynamics in past decades among children and adolescents, 
both in developed and developing countries ${ }^{(36,37)}$. A systematic review published recently showed that the association between socio-economic level and overweight is inverse in developed countries and direct in developing countries in most studies $^{(9)}$. Specifically, among studies with Brazilian adolescents that identified an association between schooling of parents, head of household or of mother and overweight, there was no consensus between the criteria employed and the results found ${ }^{(38-40)}$. Completing 8-10 years of schooling, which encompasses heads of households who finished primary education but did not complete high school, may represent a part of the population studied who did not undergo food deprivation, but who still did not have healthier life habits due to lack of information, cultural or social values or economic conditions within the context. Furthermore, adolescents in developing countries also have bad food habits and their nutritional practice is not in accordance with their knowledge $^{(41)}$. The absence of an association in our study may be due to the homogeneity of the target population with regard to socio-economic markers (at least for total appliances, about $67 \%$ of the adolescents had between six and eight appliances in their households) or could effectively express the current status of this association in this group. However, we did not find studies in Brazil with similar results.

It should be noted that the presence of both parents at home reduced the chance of overweight among the adolescents studied. This characteristic may be related to a higher socio-economic level of families and/or closer monitoring of the behaviours of adolescents, including their diets, which could promote the adoption of healthier habits.

We did not find a positive association between overweight and food consumption characteristics mentioned previously in the literature such as the frequency of consumption of soft drinks, the habit of having breakfast and the number of meals. This result may be explained by the nature of the indicators analysed, given there was no quantification of consumption or a more detailed list of foods, and by the low reliability observed in this block of variables (detailed further below).

Practising physical activity outside school on at least $1 \mathrm{~d}$ in the past $7 \mathrm{~d}$ was shown to be a protective factor against overweight, which corroborates other studies that have already demonstrated the effectiveness of the practice of physical activity in the prevention and treatment overweight in many parts of the world ${ }^{(42)}$.

Some aspects of the present study with greater potential for the occurrence of systematic errors are now examined. The estimated sample size ( $n$ 1700) was not the effectively studied sample ( $n$ 1632); however, the losses were small and we believe they did not affect the identification of associations. The goal of imputation was reached given that: (i) the distribution of data was conditionally preserved in relation to ancillary variables adopted for imputation; and (ii) the results extracted were not compromised by the imputation procedure. The modelling process (simple and multiple regressions) with the variable of years of schooling completed by the head of household and the outcome was conducted without and with values imputed, in order to identify a potential distortion of results due to the imputation. We observed that the association between this variable and overweight remained in the same direction in both situations; moreover, the estimate of POR was not significant in both the simple and the multiple regression analyses when the variable without imputed values was used, which suggests that the imputation contributed to the recovery of the expected variance in the population. No studies were conducted to assess the validity of the questionnaires used. However, other measures to control data quality were adopted, like the training, standardization and re-training of field researchers. We also performed a reliability study for the questionnaire answered by students. Lower $\kappa$ values were observed for the variables related to food consumption and behaviours. The low reliability observed for this issue may be due to the existence of different categories in answer choices, days and times, which may have been understood differently by adolescents in the two moments they answered the questionnaire. One of the consequences of this result could be the underestimation of the measurement of association. Furthermore, it should be noted that the study design (cross-sectional) used herein does not allow one to consider the associations observed here as causal associations, because there was no guarantee of time precedence of exposures in relation to outcomes.

Finally, we highlight that there is scarce information in the literature about variables that refer to the school food environment and their possible effects on overweight. Some studies conducted in developed countries have analysed the effect of ecological indicators based on individual measures of school neighbourhoods or location on overweight ${ }^{(15,29)}$. In Rio de Janeiro this type of indicator may lead to false conclusions, because a relevant portion of the students of municipal public schools live in areas close to schools, but have social and quality-of-life indicators that are very different from the areas where schools are located. Still, even when they live in the same neighbourhood, there are major social differences within.

We recommend that the results of the present study be taken into account in health promotion and overweight prevention actions in the municipal schools of the city of Rio de Janeiro. We also consider that evaluation of the effect of the school environment on populations with a more heterogeneous socio-economic profile, using other methods such as the analysis of social contact networks, could provide a better understanding about the occurrence of overweight among adolescents.

\section{Acknowledgements}

The data analysed herein are from the 'II Health Risk Factors Surveillance Survey Students of Rio de Janeiro', 
which was funded by the National Research Council of Brasil (CNPq, Universal Notice 2006, Case No. 478,262/ 2006-0). The authors declare no potential or real conflicts of interest in this study. L.O.C. was responsible for the study design, analysis and interpretation and discussion of the results, and writing the manuscript. F.S.G. participated in the analysis and interpretation of data and revision of the manuscript. I.C.L. and I.R.R.C. participated in the study design, analysis and interpretation of the data, and critical revision of the article. The authors thank Professor Carlos Augusto Monteiro from São Paulo University for his important contribution in the interpretation of results and also for his valuable suggestions on the final version of the manuscript.

\section{References}

1. World Health Organization (2008) Controlling the global obesity epidemic. http://www.who.int/nutrition/topics/ obesity/en/ (accessed July 2009).

2. Wilde JA, van Dommelen P, Middelkoop BJ et al. (2009) Trends in overweight and obesity prevalence in Dutch, Turkish, Moroccan and Surinamese South Asian children in the Netherlands. Arch Dis Child 94, 795-800.

3. Tambalis KD, Panagiotakos DB, Kavouras SA et al. (2010) Eleven-year prevalence trends of obesity in Greek children: first evidence that prevalence of obesity is leveling off. Obesity (Silver Spring) 18, 161-166.

4. Péneau S, Salanave B, Maillard-Teyssier L et al. (2009) Prevalence of overweight in 6- to 15-year-old children in central/western France from 1996 to 2006: trends toward stabilization. Int J Obes (Lond) 33, 401-407.

5. World Health Organization (2003) Global Strategy on Diet, Physical Activity and Health. http://www.who.int/hpr/ NPH/docs/gs_obesity.pdf (accessed July 2009).

6. Instituto Brasileiro de Geografia e Estatística (2004) Pesquisa de Orçamentos Familiares - POF 2002-2003 (Analysis of household food availability and nutritional status in Brazil). http://www.ibge.gov.br/home/estatistica/ populacao/condicaodevida/pof/2002analise/default.shtm (accessed December 2009).

7. Agras WS \& Mascola AJ (2005) Risk factors for childhood overweight. Curr Opin Pediatr 17, 648-652.

8. Moreno LA \& Rodriguez G (2007) Dietary risk factors for development of childhood obesity. Curr Opin Clin Nutr Metab Care 10, 336-341.

9. Cardoso LO, Engstrom EM, Leite IC et al. (2009) Socioeconomic, demographic, environmental and behavioral factors associated with overweight in adolescents: a systematic literature review. Rev Bras Epidemiol 12, 378-403.

10. Corvalán C, Kain J, Weisstaub G et al. (2009) Impact of growth patterns and early diet on obesity and cardiovascular risk factors in young children from developing countries. Proc Nutr Soc 68, 327-337.

11. Victora CG \& Barros FC (2001) Commentary: The catch-up dilemma - relevance of Leitch's 'low-high' pig to child growth in developing countries. Int J Epidemiol 30, 217-220.

12. Barbiero SM, Pellanda LC, Cesa CC et al. (2008) Overweight, obesity and other risk factors for IHD in Brazilian schoolchildren. Public Health Nutr 12, 710-715.

13. Estima CCP, Costa RS, Sichieri R et al. (2009) Meal consumption patterns and anthropometric measurements in adolescents from a low socioeconomic neighborhood in the metropolitan area of Rio de Janeiro, Brazil. Appetite 52 , $735-739$

14. Swinburn B, Egger G \& Raza F (1999) Dissecting obesogenic environments: the development and application of a framework for identifying and prioritizing environmental interventions for obesity. Prev Med 29, 563-570.

15. Lee N, Anindya K \& Simon PA (2006) School-based physical fitness testing identifies large disparities in childhood overweight in Los Angeles. J Am Diet Assoc 106, 118-121.

16. Castro IRR, Cardoso LO, Engstrom EM et al. (2008) Surveillance of risk factors for non-communicable disease among adolescents: the experience in Rio de Janeiro, Brazil. Cad Saude Publica 24, 2279-2285.

17. Kann L, Kinchen SA, Williams BI et al. (2000) Youth risk behavior surveillance - United States, 1999. MMWR CDC Surveill Summ 49, Suppl., 5, 1-32.

18. UNICEF (2001) The State of Health Behaviour and Lifestyle of Pacific Youth. Vanuatu Report. Suva, Fiji: UNICEF Pacific.

19. Landis JR \& Koch GG (1977) The measurement of observer agreement for categorical data. Biometrics 33, 159-174.

20. Lohman TG, Roche AF \& Martorell R (1988) Anthropometric Standardization Reference Manual. Champaign, IL: Human Kinetics Books.

21. Habitch JP (1974) Estandarizacion de métodos epidemiológicos cuantitativos sobre el terreno. Bol Oficina Sanit Panam 76, 375-384.

22. De Onis M, Onyango AW, Borghi E et al. (2007) Development of a WHO growth reference for school-aged children and adolescents. Bull World Health Organ 85, 660-667.

23. Silva PLN (1989) Review and imputation for quantitative data using SAS. Master's Thesis, Instituto Nacional de Matemática Pura e Aplicada.

24. Breiman L, Friedman JH \& Olshen RA (1984) Classification and Regression Trees. Monterey, CA: Wadsworth International Group.

25. Lauritsen JM (2000-2008) EpiData Data Entry, Data Management and Basic Statistical Analysis System. Odense: EpiData Association.

26. Snijders T \& Bosker T (1999) Multilevel Analysis. An Introduction to Basic and Advanced Multilevel Modeling. London: Sage Publications.

27. Goldstein H (2003) Multilevel Statistical Models. New York: Oxford University Press Inc.

28. O'Malley PM, Johnston LD, Delva J et al. (2007) Variation in obesity among American secondary school students by school and school characteristics. Am J Prev Med 33, 4 Suppl., S187-S194.

29. Richmond TK \& Subramanian SV (2008) School level contextual factors are associated with the weight status of adolescent males and females. Obesity (Silver Spring) 16, $1324-1330$.

30. Kumar R, O'Malley P, Johnston L et al. (2002) Effects of schoollevel norms on student substance use. Prev Sci 3, 105-124.

31. Maes L \& Lievens J (2003) Can the school make a difference? A multilevel analysis of adolescent risk and health behaviour. Soc Sci Med 56, 517-529.

32. Moore L, Roberts C \& Tudor-Smith C (2001) School smoking policies and smoking prevalence among adolescents: multilevel analysis of cross-sectional data from Wales. Tob Control 10, 117-123.

33. Richmond T, Hayward R, Gahagan S et al. (2006) Can school income and racial/ethnic composition explain the racial/ethnic disparity in adolescent physical activity participation? Pediatrics 117, 2158-2166.

34. Anon. (2009) Lei 11947 de 16/06/2009. Diário Oficial da União no. 113, seção 1.

35. Maldonado LA, Azevedo AMF \& Castro IRR (2007) The School Food Program as a strategy to promote health in 
Rio de Janeiro. In Ministry of Health/Pan American Health Health Promoting Schools: Experiences from Brazil. Brasília: Ministry of Health, pp. 106-112; available at http://portal. saude.gov.br/portal/arquivos/pdf/esc_prom_saude.pdf

36. Shrewsbury V \& Wardle J (2008) Socioeconomic status and adiposity in childhood: a systematic review of crosssectional studies 1990-2005. Obesity (Silver Spring) 16, 275-284.

37. Matijasevich A, Victora CG, Golding J et al. (2009) Socioeconomic position and overweight among adolescents: data from birth cohort studies in Brazil and the UK. BMC Public Health 9, 105.

38. Ribeiro IC, Colugnati FAB \& Taddei JAAC (2009) Risk factors for overweight among adolescents: analysis of three Brazilian cities. Rev Nutr 22, 503-515.
39. Vanzelli AS, Castro CT, Pinto MS et al. (2008) Prevalence of overweight and obesity among children of public schools in the city of Jundiaí, São Paulo, Brazil. Rev Paul Pediatr 26, 48-53.

40. Fernandes RA, Codogno JS, Cardoso JR et al. (2009) Factors associated with overweight among adolescents in different school systems in the municipality of Presidente Prudente in the State of São Paulo. Rev Bras Saude Matern Infantil 9, 443-449.

41. Mirmiran P, Azadbakht L \& Azizi F (2007) Dietary behaviour of Tehranian adolescents does not accord with their nutritional knowledge. Public Health Nutr 10, 897-901.

42. Reichert FF, Baptista Menezes AM, Wells JC et al. (2009) Physical activity as a predictor of adolescent body fatness: a systematic review. Sports Med 39, 279-294. 